\title{
STUDY IN DEPENDENCE OF OPERATING MODE ON COMPLETENESS OF HAULM REMOVAL
}

\author{
Dinar Ismagilov $^{1}$, Marat Kalimullin ${ }^{1}$, Rafkat Latypov ${ }^{2}$, Rashit Gilfanov ${ }^{3}$, Ilshat Mukhametshin ${ }^{1}$ \\ ${ }^{1}$ Kazan State Agrarian University, Russia; ${ }^{2}$ South Ural State Agrarian University, Russia; ${ }^{3}$ Kazan State \\ University of Architecture and Civil Engineering, Russia \\ marat-kmn@yandex.ru
}

\begin{abstract}
Row and industrial crops in the overall structure of crop production occupy a significant share. A special role is assigned to the production of root and tuber crops. A distinctive feature of the technology of cultivation of root and tuber crops is that before or during harvesting the tops are removed. The article presents the results of experimental studies to substantiate and assess the effect of the kinematic operating mode of a rotary topper chopper on the completeness of removing the tops of root and tuber crops. As the factors determining the percentage of completeness of haulm removal, the rotor speed and the speed of the haulm chopper were chosen. These factors, along with the diameter of the cross-section of the working element, have the greatest influence on the quality of the implementation of the technological process of grinding the tops of potatoes with the simultaneous destruction of the larvae of the Colorado potato beetle. During the experiments, the methodology of the mathematical theory of planning experiments was used. To process the experimental results, we used the software developed by the authors in the Visual Basic for Aplications language in the MS Excel environment. With the help of the constructed mathematical model, the optimization problem was solved and the values of the operating parameters of the topper chopper were determined, which ensure the maximum percentage of the completeness of the haulm removal. The values of the operating parameters of the topper chopper, at which the highest percentage of haulm removal is achieved, turned out to be as follows: rotor speed $-1750.340 \mathrm{~min}^{-1}$; $\mathrm{speed}^{-1}$ of movement of the unit $-2.922 \mathrm{~m} \cdot \mathrm{s}^{-1}$.
\end{abstract}

Keywords: tops, root crops, rotary toppers, full-factor experiment plan, optimization problem.

\section{Introduction}

The demand for ecological products grown using the technology of minimal chemical treatments is growing from year to year [1;2]. Crop productivity is the result of the interaction of many factors and conditions, the most important of which are: soil fertility, plant nature, soil and climatic conditions and mechanized tillage technology [3-5].

The justification of the technology and complex of machines for potato cultivation must be based on the condition of the technical base and workforce management, soil and climatic conditions, the financial situation of the economy and considering of the requirements for soil treatment, crop rotation, seed material, its preparation, planting and care during the growing season and a number of other organizational and technological problems [6-8].

A distinctive feature of the technology of cultivation of root and tuber crops is that before or during harvesting the tops are removed [9-11]. Removing the tops facilitates harvesting, promotes better maturation of potato tubers, reduces the possibility of transferring fungal and viral diseases of root crops, which reduces the sensitivity of the latter to mechanical damage and loss of production during longterm storage [12-13].

The existing machines Bargam, Structural, Grimme, BDM either cannot ensure the performance of work in accordance with agrotechnical requirements, or are energy-intensive and expensive. In this regard, it seems promising to develop rotary working bodies of a cable type, which ensure the required quality of removal and crushing of the tops of root and tuber crops and reduce energy consumption for the operation, simplify the drive of the working bodies and the metal consumption of the machine structure as a whole [14-16].

The work solved the problem of selecting the operating modes of the topper, which ensure the highest percentage of removal of the tops of root and tuber crops.

\section{Materials and methods}

The creation of a complex of machines for energy-saving technologies and their maintenance in good condition by choosing the optimal strategy for technical service is one of the priority directions of scientific activity of the Kazan State Agrarian University. As part of this activity, a rotary chopper of root and tuber tops was developed, which is shown in Figure $1[17 ; 18]$. 

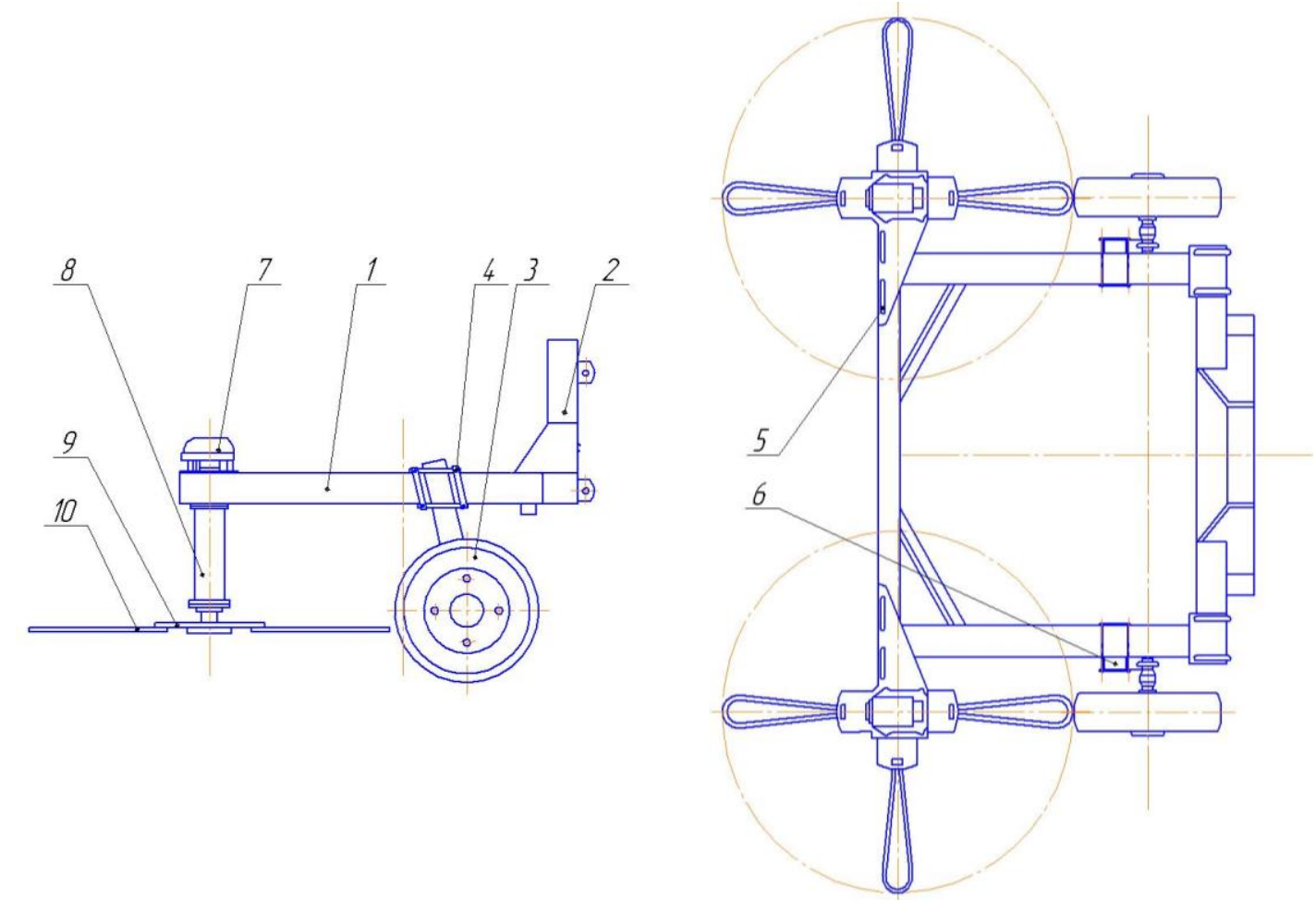

Fig. 1. General view of the rotary topper for root and tuber crops: 1 - frame, 2 - linkage mechanism; 3 - support wheel; 4 - fixing bracket; 5 - slot; 6 - an adjusting bar; 7 - hydraulic motor; 8 - vertical shaft; 9 - rotor; 10 - work item

In order to determine the most rational parameters of work, it was decided to make a mathematical model of the dependence of the completeness of the removal of tops from the rotor speed and the speed of movement of the topper. These factors, along with the diameter of the cross-section of the working element, have the greatest impact on the quality of the implementation of the technological process of grinding the tops of potatoes, with the simultaneous destruction of the larvae of the Colorado potato beetle. The impact force on the haulm depends on the speed and diameter of the working element, which affects the quality of its crushing and the completeness of removal. The diameter of the working element was selected earlier in laboratory tests on the soil canal of the Kazan State Agrarian University, therefore, when conducting field experiments, its value was taken equal to $\mathrm{d}=0.006 \mathrm{~m}$. The choice of the speed of the unit is also important, since its incorrect value leads either to a decrease in productivity, or to a deterioration in the quality of work.

The evenness of the field, the uniformity of the height of the beds, the contamination of the field, as well as the physical and mechanical properties of the soil, are also important in removing the tops. In this case, we will assume that all technological operations during the cultivation of potatoes were carried out efficiently and on time, therefore the values of the above indicators are at the required level. The potatoes were harvested using a separate method, so the cutting height of the tops was within $5 \mathrm{~cm}$.

It was decided to choose the type of relationship between the completeness of the haulm removal (response $\mathrm{z}$ ), the rotor rotation speed and the speed of the haulm chopper (factors $\mathrm{x}^{\prime}$ and $y^{\prime}$ ) in the form of a quadratic polynomial. Since, as stated in [19], second-order polynomial models allow solving the absolute majority of engineering problems in material science and technology, as a result of which they can be considered basic for engineering practice. That is, the relationship between the response $\mathrm{z}$ and the factors $x^{\prime}$ and $y$ ' was sought in the form:

$$
Z=\beta_{0}+\beta_{1} \cdot x^{\prime}+\beta_{2} \cdot y^{\prime}+\beta_{11} \cdot x^{\prime 2}+\beta_{22} \cdot y^{\prime 2}+\beta_{12} \cdot x^{\prime} \cdot y^{\prime}+\varepsilon .
$$

In the course of the experiments, the values of the factor $\mathrm{x}^{\prime}$ varied in the range from $540 \mathrm{~min}^{-1}$ to $2000 \mathrm{~min}^{-1}$, and the factor $y^{\prime}$ in the range from $2.5 \mathrm{~m} \cdot \mathrm{s}^{-1}$ to $4.3 \mathrm{~m} \cdot \mathrm{s}^{-1}$. The rotor speed in the experiments was limited to the accepted values, since its lower values do not allow chopping the tops of potatoes, which is confirmed by the research of scientists in this area, and large values lead to excessive power 
consumption of the power plant, which is confirmed by the results of the tests carried out at the Volga machine testing station [20]. The forward speed of the unit varied within the specified limits in accordance with the generally accepted values of this indicator used in the implementation of technological operations of mowing, crushing and removing the tops of potatoes. During the experiment, the surface of the plot was in good condition, the tops were green, well-developed, erect with a closed crown.

As a plan for the experiments, a plan of a full-factor experiment was chosen with a variation of each factor at three levels. A total of nine experiments in the plan: $9=3^{2}$, in addition to these experiments in the center of the plan, two additional experiments were carried out to calculate the variance of the reproducibility of the experiments. The choice of this design for conducting experiments was due to the fact that it has a fairly good efficiency in all criteria (D, A, E, Q-optimality) and is used in cases where there are no strict resource constraints. It has a sufficiently high redundancy of experiments: to obtain estimates of the six parameters of the model (1), nine experiments are performed, which allows to obtain statistically reliable conclusions. The planning matrix and the results of the experiments to substantiate and assess the effect of the kinematic operating mode of the rotary topper chopper on the completeness of the haulm removal are presented in Table 1.

Planning matrix and experiment results

Table 1

\begin{tabular}{|c|c|c|c|c|c|}
\hline \multirow{2}{*}{ Experiment } & \multicolumn{2}{|c|}{$\begin{array}{c}\text { Rotor rotation speed, } \\
\text { min }^{-1}\end{array}$} & \multicolumn{2}{c|}{$\begin{array}{c}\text { Topper movement speed, } \\
\mathbf{m} \cdot \mathbf{s}^{-\mathbf{1}}\end{array}$} & $\begin{array}{c}\text { Percentage of } \\
\text { haulm removal, \% }\end{array}$ \\
\cline { 2 - 6 } & $X^{\prime}$ & $X$ & $Y^{\prime}$ & $Y$ & $Z$ \\
\hline 1 & 540 & -1 & 2.5 & -1 & 58 \\
\hline 2 & 2000 & +1 & 2.5 & -1 & 98 \\
\hline 3 & 540 & -1 & 4.3 & +1 & 23 \\
\hline 4 & 2000 & +1 & 4.3 & +1 & 80 \\
\hline 5 & 540 & -1 & 3.4 & 0 & 52 \\
\hline 6 & 2000 & +1 & 3.4 & 0 & 96 \\
\hline 7 & 1270 & 0 & 2.5 & -1 & 92 \\
\hline 8 & 1270 & 0 & 4.3 & +1 & 70 \\
\hline 9 & 1270 & 0 & 3.4 & 0 & 90 \\
\hline 10 & 1270 & 0 & 3.4 & 0 & 89 \\
\hline 11 & 1270 & 0 & 3.4 & 0 & 91 \\
\hline
\end{tabular}

Here $x$ and $y$ are coded values of factors $x^{\prime}$ and $y^{\prime}$. They are expressed through the natural values of the factors according to the formulas:

$$
\begin{gathered}
X=\frac{2 \cdot\left(X^{\prime}-X_{c p}^{\prime}\right)}{\left(X_{\max }^{\prime}-X_{\text {min }}^{\prime}\right)}, \\
Y=\frac{2 \cdot\left(Y^{\prime}-Y_{c p}^{\prime}\right)}{\left(Y_{\max }^{\prime}-Y_{\text {min }}^{\prime}\right)},
\end{gathered}
$$

where $x_{\text {mid }}^{\prime}=\left(x_{\text {min }}^{\prime}+x_{\text {max }}^{\prime}\right) / 2, y^{\prime}{ }_{\text {mid }}=\left(y_{\text {min }}^{\prime}+y_{\text {max }}^{\prime}\right) / 2 ; x_{\text {min }}^{\prime}, y_{\text {min }}^{\prime}, x_{\text {max }}^{\prime} y_{\text {max }}^{\prime}-$ mean values in physical terms of factors $x^{\prime}$ and $y^{\prime}$, respectively;

$x_{\text {min }}^{\prime}, y_{\text {min }}^{\prime}, x_{\text {max }}^{\prime} y_{\text {max }}^{\prime}-$ minimum and maximum values of factors $x^{\prime}$ and $y^{\prime}$ in physical units, respectively.

By substituting the values of the factors $x^{\prime}$ and $y^{\prime}$ into formulas (2) and (3), it is easy to make sure that the values of the coded factors $\mathrm{x}$ and $\mathrm{y}$ vary in the range from -1 to +1 .

\section{Results and discussion}

As a result of processing the experimental data (Table 2), using special software written in the Visual Basic for Aplications language in the MS Excel environment, the following mathematical model was obtained in coded variables: 


$$
\begin{aligned}
& \bar{z}=b_{0}+b_{1} \cdot x+b_{2} \cdot y+b_{11} \cdot x^{2}+b_{22} \cdot y^{2}+b_{12} \cdot x \cdot y= \\
& 90.0526+23.5 \cdot x-12.5 \cdot y-16.1316 \cdot x^{2}-9.1316 \cdot y^{2}+4.25 \cdot x \cdot y
\end{aligned}
$$

Experimental data processing results

Table 2

\begin{tabular}{|c|c|c|c|c|c|c|c|c|c|c|}
\hline Experiment & $\boldsymbol{X}$ & $\boldsymbol{Y}$ & $\boldsymbol{X} 2$ & $\boldsymbol{Y} 2$ & $\boldsymbol{X} \cdot \boldsymbol{Y}$ & $\boldsymbol{Z e x p}$ & $\boldsymbol{Z c a l c}$ & $\boldsymbol{E} \boldsymbol{i}$ & $\boldsymbol{A i}$ & $\boldsymbol{A b s}(\boldsymbol{A i})$ \\
\hline 1 & -1 & -1 & 1 & 1 & 1 & 58 & 58.03947 & -0.03947 & -0.06806 & 0.068058 \\
\hline 2 & 1 & -1 & 1 & 1 & -1 & 98 & 96.53947 & 1.460526 & 1.490333 & 1.490333 \\
\hline 3 & -1 & 1 & 1 & 1 & -1 & 23 & 24.53947 & -1.53947 & -6.69336 & 6.693364 \\
\hline 4 & 1 & 1 & 1 & 1 & 1 & 80 & 80.03947 & -0.03947 & -0.04934 & 0.049342 \\
\hline 5 & -1 & 0 & 1 & 0 & 0 & 52 & 50.42105 & 1.578947 & 3.036437 & 3.036437 \\
\hline 6 & 1 & 0 & 1 & 0 & 0 & 96 & 97.42105 & -1.42105 & -1.48026 & 1.480263 \\
\hline 7 & 0 & -1 & 0 & 1 & 0 & 92 & 93.42105 & -1.42105 & -1.54462 & 1.544622 \\
\hline 8 & 0 & 1 & 0 & 1 & 0 & 70 & 68.42105 & 1.578947 & 2.255639 & 2.255639 \\
\hline 9 & 0 & 0 & 0 & 0 & 0 & 90 & 90.05263 & -0.05263 & -0.05848 & 0.05848 \\
\hline 10 & 0 & 0 & 0 & 0 & 0 & 89 & 90.05263 & -1.05263 & -1.18273 & 1.182732 \\
\hline 11 & 0 & 0 & 0 & 0 & 0 & 91 & 90.05263 & 0.947368 & 1.041064 & 1.041064 \\
\hline
\end{tabular}

From where, $S_{\text {repr }}^{2}=2, A_{\text {mid }}=1.852949$.

The calculated values of the Student's criterion for the coefficients are presented in Table 3.

Calculated values of the Student's test for the coefficients

Table 3

\begin{tabular}{|c|c|c|c|c|c|c|}
\hline Coefficient & $\boldsymbol{t}_{0}$ & $\boldsymbol{t}_{1}$ & $\boldsymbol{t}_{2}$ & $\boldsymbol{t}_{11}$ & $\boldsymbol{t}_{22}$ & $\boldsymbol{t}_{12}$ \\
\hline Student's criterion & 135.0789 & 35.25 & 18.75 & 24.19737 & 13.69737 & 6.375 \\
\hline
\end{tabular}

Significant coefficients of the mathematical model are presented in Table 4.

Table 4

Significant coefficients of the mathematical model

\begin{tabular}{|c|c|c|c|c|c|c|}
\hline Coefficient & $\boldsymbol{B}_{0}$ & $\boldsymbol{B}_{1}$ & $\boldsymbol{B}_{2}$ & $\boldsymbol{B}_{11}$ & $\boldsymbol{B}_{22}$ & $\boldsymbol{B}_{12}$ \\
\hline Coefficient value & 90.05263 & 23.5 & -12.5 & -16.1316 & -9.13158 & 4.25 \\
\hline
\end{tabular}

The calculated value of the Fisher coefficient is $F_{\text {calc }}=0.70634$.

All coefficients in model (4) are significant, since the calculated values of the Student's criterion for them are greater than the critical value of the Studen's criterion for the significance level $\alpha=0.05$ and the degree of freedom number $\mu=n(m-1)=91) t_{c r}=t(0.05 ; 9)=2.262$. The model is adequate since $F_{\text {calc }}=0.706$; and the critical value of the Fisher criterion for the significance level $\alpha=0.05$ and the number of degrees of freedom $k_{1}=n-1=9-6=3 ; k_{2}=n \quad(m-1)=9 \quad(2-1)=9$ is $F_{c r}=F$ $(0.05 ; 3 ; 9)=3.900$ and $F_{\text {calc }}<F_{c r}$. Model (4) is also adequate according to the criterion of the average relative error, since $A_{\text {mid }}=1.853 \%<10 \%$. Model (4) is adequate according to two criteria, therefore, with a sufficient degree of reliability, it can be used to predict the values of the response $z$ for the values of the factors $x$ and $y$ from their ranges of variation, but not found in the plan matrix. Also, model (4) can be used to solve the optimization problem.

The optimization problem is formulated as follows: to select such values of the rotor speed and the speed of the topper that provide the maximum percentage of haulm removal. The mathematical formulation of this problem is as follows:

$$
F(x, y)=\left(90.0526+23.5 \cdot x-12.5 \cdot y-16.1316 \cdot x^{2}-9.1316 \cdot y^{2}+4.25 \cdot x \cdot y\right) \rightarrow \max .
$$

where $\quad-1 \leq x \leq 1,-1 \leq y \leq 1$.

The equation (5) is a conditional nonlinear programming problem. Its solution by the conjugate gradient method in conjunction with the penalty function method [21], using the "Search for a solution" add-in of the MS Excel spreadsheet processor, leads to the following result:

$$
x_{\text {opt }}=0.658, y_{\text {opt }}=-0.531 \text { wherein } F\left(x_{\text {opt }}, y_{\text {opt }}\right)=101.109 \% \text {. }
$$


Indirectly, the correctness of the solution to the optimization problem (5) is confirmed in Figure 2, which shows the surface of the dependence $F(x, y)$.

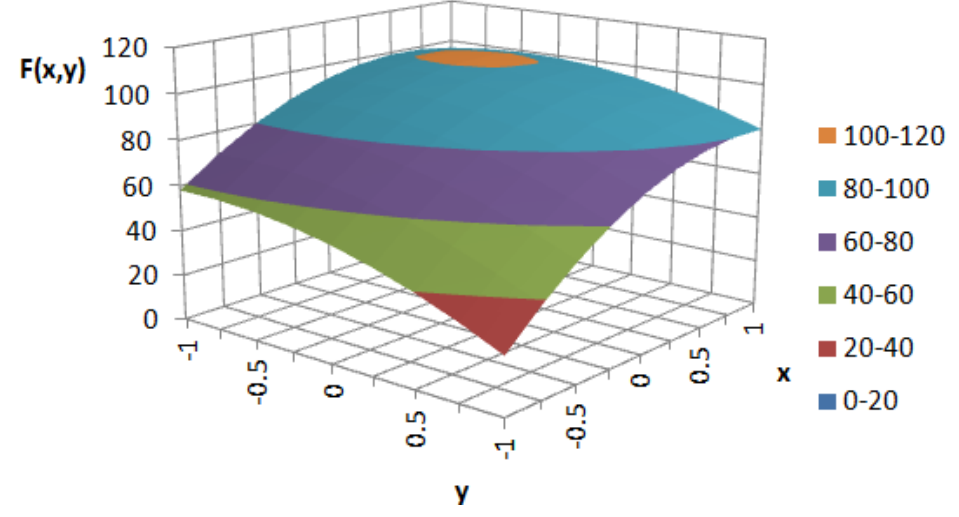

Fig. 2. Graph $z=F(x, y)$ of the dependence of complete removal of the haulm from the speed of movement and the rotational speed of the haulm chopper

As it can be seen from the result of solving the problem, the percentage of haulm removal is $101.109 \%$, which is not physically realizable. The explanation for this is the following: the model predicts the percentage of haulm removal is not absolutely accurate - the maximum model error at the plan points is $\approx 2.0 \%$. As it can be seen from the data in Table 1, approximately the same error is observed in the accuracy of the reproduction of the experiments in the centre of the plan. Therefore, taking this into account, we take the percentage of tops removal at equal to $\approx 100 \%$. To determine the natural values of the operating parameters at which the greatest percentage of haulm removal is achieved, we will use formula (2). From it we obtain expressions for finding the natural values of the parameters through their coded values:

$$
\begin{aligned}
& x_{o n m}^{\prime}=x_{c p}^{\prime}+\frac{x_{o n m}}{2} \cdot\left(x_{\text {max }}^{\prime}-x_{\text {min }}^{\prime}\right), \\
& y_{o n m}^{\prime}=y_{c p}^{\prime}+\frac{y_{o n m}}{2} \cdot\left(y_{\text {max }}^{\prime}-y_{\text {min }}^{\prime}\right) .
\end{aligned}
$$

Substituting the values $x_{o p t}=0.658 ; y_{\text {opt }}=-0.531$ in formulas (6) and (7), we find:

$$
\begin{gathered}
x_{o p t}^{\prime}=x_{\text {mid }}^{\prime}+\frac{x_{o p t}}{2} \cdot\left(x_{\max }^{\prime}-x_{\min }^{\prime}\right)=1270.000+\frac{0.658}{2} \cdot(2000.000-540.000)=1750.340 ; \\
y_{o p t}^{\prime}=y_{\text {mid }}^{\prime}+\frac{y_{o p t}}{2} \cdot\left(y_{\text {max }}^{\prime}-y_{\text {min }}^{\prime}\right)=3.400+\frac{(-0.531)}{2} \cdot(4.300-2.500)=2.922 .
\end{gathered}
$$

\section{Conclusions}

The natural values of the operating parameters of the topper chopper, at which the highest percentage of haulm removal, equal to approximately $100 \%$, is achieved, turned out to be as follows: $x_{\text {opt }}^{\prime}=1750.340 \mathrm{~min}^{-1} ; y_{\text {opt }}^{\prime}=2.922 \mathrm{~m} \cdot \mathrm{s}^{-1}$. The constructed mathematical model reproduces the experimental data quite accurately, which makes it possible to use it in further research.

\section{Acknowledgements}

The study is supported by the grant of the President of the Russian Federation for young scientistsdoctors of sciences MD-6281.2021.4.

\section{References}

[1] Byshov N.V., Borychev S.N., Simdyankin A.A. etc. Modern view on potato production Polythematic network electronic scientific journal of the Kuban State Agrarian University, No. 128, 2017, pp. 146-153. 
[2] Osowski J. Innovation and optimization in potato cultivation protection. Zywnosc. Nauka. Technologia. Jakosc/Food. Science Technology. Quality. 25. pp. 42-55. DOI: 10.15193/zntj/2018/117/258.

[3] Yaropud V., Volyk B. Rationale for the needle disc design of a rotary harrow with the analysis of the structure of the body of a biological analogue. Vibrations in engineering and technology. 2019, pp. 56-64. DOI: 10.37128/2306-8744-2019-4-7.

[4] Sheichenko V., Dudnikov I., Shevchuk V., Kuzmych A. Research of surface-plane and spacedeep interaction of needle with soil. Agricultural machinery. Proceedings. "Uses of machines. Innovative technologies. Conserving soils and water." VII International Scientific congress. Vol.2. ScientificTechnical Union of Mechanical Engineering industry 4.0. 26-29 JUNE 2019, BURGAS, BULGARIA, pp. 93-96.

[5] Hirasawa K., Kataoka T., Kubo T. Prediction and evaluation for leveling performance in rotary tiller. Proc. 4th IFAC Conference on Modelling and Control in Agriculture, Horticulture and Post Harvest Industry, Espoo, Finland, 46, 2013, pp. 315-320.

[6] Raparelli T., Pepe G., Ivanov A., Eula G. Kinematic analysis of rotary harrows. Journal of Agricultural Engineering, vol. 976, No. 1, 2019, pp.9-14.

[7] Maximov L.M., Maximov P.L., Maximov L.L. (2009). A new way of separating potato tubers from soil and tops. The rural machine operator. No. 3, 2009, pp. 6-7.

[8] Pervushin VF, Ivanov AG, Salimzyanov MZ. Modeling of the grinder of potato tops. Mechanization and electrification of agriculture. No. 6, 2010, pp. 2-3.

[9] Pervushin VF, Ivanov AG, Salimzyanov MZ. Determination of the rotational speed of the rotor of the chopper of potato tops. Mechanization and electrification of agriculture. No. 9, 2010, pp. 4-5.

[10] Uglanov MB, Bachurin AN, Byshov DN, Abramov Yu.N. The study of the modernized bd-4m botodrobitel with hinged knives. Political Mathematical Network Electronic Scientific Journal of the Kuban State Agrarian University. No. 128, 2017, pp. 200-213.

[11] Karpov M.V., Shardina G.E., Zhizdyuk A. A. Study of the effectiveness and economic evaluation of the application of the developed potato planting machine Agricultural scientific journal №4, 2018, pp 41-47.

[12] Rembalovich G.K., Byshov N.V., Borychev S.N. etc. Innovative solutions harvesting and transport technological processes and technical means in potato Agricultural machinery and technologies, No. 1, 2013, pp. 23-25.

[13] Shardina GE, Karpov MV 2011 Justification kinematical parameters spoon-belt apparatus are planted Scientific Review, № 4, p. 117.

[14] Bulgakov V., Aboltins A., Beloev H., etc. Experimental investigation of plow-chopping unit. Agriculture (Switzerland), No. 11(1), 2021, pp. 1-14.

[15] S.S.Tubolev etc. Machine technologies and equipment for potato production (Moscow: Agrospas), $1995,316 \mathrm{p}$.

[16] Semenov, A. V., Novikov A.M. The effectiveness of seed germination in the cultivation of early potatoes Bulletin of the Chuvash State Agricultural Academy, No 2(5), 2018, pp 22-26.

[17] Kalimullin, M., Abdrakhmanov, R., Latypov, R., Salimzyanov, M., Sharipov, R. Combined units for mowing and sealing of siderates IOP Conference Series: Earth and Environmental Science, No. 604 (1), 2020, 012028.

[18] Kalimullin M, Ismagilov D, Abdrakhmanov R. To question of determining design parameters of working body of rotary chopper of tops. Engineering for Rural Development. No. 19, 2020, 1224 p.

[19] Bulgariev G.G., Kalimullin M.N., Abdrakhmanov R.K., Khamitov R.R. Kinematic of the toothed rotational operating element's movement Bulletin of Kazan State Agrarian University, No. 3 (41), 2016, pp. 68-71.

[20] Kalimullin M., Abdrakhmanov R., Andreev R., etc. Improvement of potato cultivation technology IOP Conference Series: Earth and Environmental Science, 2019, P. 012017.

[21] Kalimullin M.N., Abdrakhmanov R.K., Arkhipov S.M. Rotary haulm chopper parameters development and substantiation for root and tuber crops International Journal of Applied Engineering Research, Vol. 10, No. 10, 2015, pp. 25691-25697. 